American Journal of Geoscience 1 (1): 12-20, 2010

ISSN 1948-9846

(C) 2010 Science Publications

\title{
Soil-moisture Retention Characteristics of Earth Materials in the Weathering Profile over a Porphyritic Biotite Granite
}

\author{
John Kuna Raj \\ Department of Geology, University of Malaya, 50603 Kuala Lumpur, Malaysia
}

\begin{abstract}
Problem statement: Three broad morphological zones and several sub-zones were differentiated within the weathering profile based on variations in earth materials and the degree of preservation of original bedrock minerals, textures and structures. Approach: The topmost Zone I (Grade 6) is some $12 \mathrm{~m}$ thick and comprises completely weathered bedrock materials (mainly a stiff, clayey sand) with indistinct relict bedrock textures. Results: The intermediate Zone II (Grades 3, 4 and 5) is some $30 \mathrm{~m}$ thick and consists of in situ, moderately to highly weathered bedrock materials (mostly friable, gravelly silty sands and coreboulders) that indistinctly to distinctly preserve the original bedrock minerals, textures and structures; the degree of preservation increasing with depth. The bottom Zone III (Grade 2) consists of continuous bedrock with effects of weathering only along and between structural discontinuity planes; the earth materials of zones I and II thus representing the residual soil over bedrock. Constant volume samples show a general increase in porosity, silt and clay fractions up the weathering profile, but a corresponding decrease in the sand and gravel fractions with sub-zone IC having the highest density and lowest porosity. Soil-moisture retention curves, determined with the pressure plate method, show increasing suctions from $0-4.19 \mathrm{pF}(0$ to $-1,500 \mathrm{kPa})$ with decreasing moisture contents of $35-18 \%$ for sub-zone IC samples, $32-7 \%$ for sub-zone IIB samples and some $25-4 \%$ for sub-zone IID samples. Conclusion/Recommendations: These soil-moisture retention variations reflect textural differences and point to the inherent role of suction in the unsaturated earth materials. Differences in the volumes of calculated drainage and storage pores indicate that the earth materials of sub-zone IC will have the lowest rates of infiltration and percolation, whilst those of subzone IID will have the fastest rates and those from sub-zone IIB, intermediate rates.
\end{abstract}

Key words: Morphological zonation, weathering profile, unsaturated soils, suction variation

\section{INTRODUCTION}

In humid tropical areas as Peninsular Malaysia, high temperatures, moderate to high rainfalls, low surface denudation rates and stable landscapes of considerable antiquity have provided a geomorphological bias that has allowed for deep weathering (Raj, 2009). As weathering occurs in situ, the weathered materials have accumulated at the sites of formation and given rise to thick mantles of weathered materials (or regoliths) over bedrock. Variations in the degree of preservation of the minerals, textures and structures of the original bedrock are seen in the regoliths; the vertical sequence of materials of different composition extending upwards to the ground surface from the unaltered bedrock below being known as the weathering profile (Raj, 2009).

The weathering profiles are found in undulating to hilly and mountainous terrain and often considered to be equivalent with 'residual soils', though the term 'residual soil' should strictly only refer to that part of the weathering profile whose economic excavation would not require the use of explosives (United States Bureau of Reclamation, 1974). Weathering profiles furthermore, are usually located above zones of unconfined groundwater and they have thus been called "unsaturated soils" in geotechnical literature; such soils being characterized by the presence of suction (or negative pore-water pressures) (Ali et al., 2005). The relationship between moisture content and suction is expressed by the soil-water characteristic curve and is a fundamental relationship that needs to be determined in investigations of unsaturated soils (Vanapalli et al., 1996). The soil-water characteristic curve is also important in agriculture, though here, it is known as the soil-moisture retention curve. Knowledge of the moisture retention characteristics of soils is essential to the daevelopment of effective irrigation and plant stress management techniques as suction/water relationships directly affect yield and quality of crops (Wild, 1993).

There is limited published data on the soil-moisture retention characteristics of earth materials in Malaysia; there only being a single unpublished report describing the soil-moisture retention capabilities (determined with 
the pressure plate method) of samples from saprolites (morphological sub-zone IC) over weathered granite, schist, slate and basalt in Peninsular Malaysia. The soilwater characteristic curve (determined with a modified Rowe Cell) of a sandy clay sample from sub-zone IC of the weathering profile being discussed was presented in an unpublished thesis and also shown in a later published research (Mohamed et al., 2006). In the published research (Mohamed et al., 2006), results of a series of direct shear tests with fixed suction were presented and it was concluded that suction plays a role in increasing the shear strength of unsaturated soil; there being a non-linear failure envelope due to the non-linear soil-water characteristic curve.

There is also limited published data on the soilwater retention characteristics of earth materials in neighboring, humid tropical areas. A single published study, that discusses the soil-water characteristic curves of 'residual soils' over the sedimentary Jurong Formation and Bukit Timah Granite of Singapore Island, has concluded that the depth of weathering did not have a consistent effect on both sets of curves, though soils over the Granite had a wider range of pore sizes (Agus et al., 2001). Several multi-variate empirical equations using a number of basic soil properties to estimate the soil-water characteristic curves of Singapore residual soils were also proposed in this study (Agus et al., 2001).

Published literature on topics related to soilmoisture retention characteristics of earth materials in Malaysia include a study that discusses the modifications to the standard shear box that allowed the testing of samples in unsaturated conditions (Bujang et al., 2005). Results of a series of direct shear tests with fixed suction on Grade VI weathered materials from morphological sub-zone IC of the weathering profile being discussed were presented and it was concluded that the shear strength of the samples increased with an increase in applied suction (Bujang et al., 2005). Another published study described the response of suction to rainfall at the weathering profile being discussed; this profile being termed "an unsaturated residual soil slope of weathered granite” (Bujang et al., 2005).

In this study, the morphological zonation of the weathering profile over the porphyritic biotite granite bedrock is first discussed in order to define the various earth materials, as well as indistinctly to distinctly preserved minerals, textures and structures of the original bedrock, present at different levels. Variations in index properties of the earth materials are investigated through the collection of constant volume samples whilst the pressure plate method was employed to determine the soil-moisture retention characteristics of samples from different morphological sub-zones. Conclusions are reached on the variation of the soilmoisture retention characteristics of the earth materials within the weathering profile as well as the implications in terms of their shear strength.

Geological setting of investigated weathering profile: The investigated weathering profile is exposed at the slope cut at $\mathrm{Km} 31$ of the Kuala Lumpur-Karak Highway and is developed over a porphyritic biotite granite (Fig. 1). The bedrock forms part of the eastern lobe of the Late Triassic (199-210 Ma) Kuala Lumpur Granite and has given rise to a fluvially dissected, hilly to mountainous terrain of steep slopes and narrow, deep valleys. The bedrock continues to outcrop to the west over a distance of about $10 \mathrm{~km}$, but to the east, is in contact with a sequence of schists and sedimentary and volcanic rocks, that occur as a roof pendant within the Main Range Granite (Raj, 1985).

The granitic bedrock exposed at the foot of the cut is strongly jointed and cut by a number of moderately to steeply dipping faults of variable strike. A number of epidote and quartz feldspar veins with tourmaline as well as aplite and leucocratic microgranite dykes are

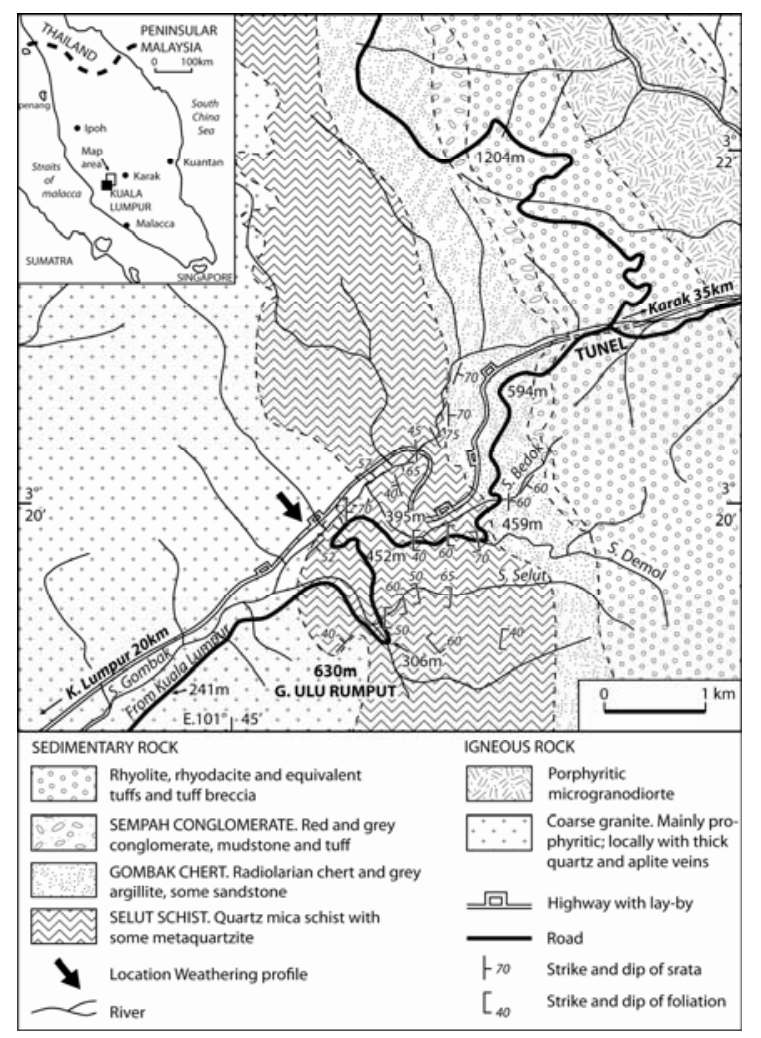

Fig. 1:Geological sketch-map of the Genting Sempah area, Pahang and Selangor (Raj, 1985) 
Am. J. Geoscience 1 (1): 12-20, 2010

Table 1: Modal analysis of porphyritic biotite granite

\begin{tabular}{lllllllll}
\hline Sample & Pheno-cryst A (\%) & Grd-mass Q (\%) & Grd-mass A (\%) & Grd-mass P (\%) & Grd-mass B (\%) & Recal. Q (\%) & Recal. A (\%) & Recal. P (\%) \\
\hline 1 & 12.3 & 26.8 & 29.1 & 24.2 & 7.5 & 29.0 & 44.8 & 26.2 \\
2 & 23.2 & 29.7 & 14.6 & 25.2 & 7.7 & 32.3 & 40.9 & 26.9 \\
\hline \multicolumn{2}{l}{ Note: } & Grd-mass refers to Groundmass; Recal. & Recalculated to $100 \%$;: Alkali feldspar, B: Biotite; P. Plagioclase feldspar; Q: Quartz
\end{tabular}

Note: Grd-mass refers to Groundmass; Recal.: Recalculated to 100\%; A: Alkali feldspar, B: Biotite; P: Plagioclase feldspar; Q: Quartz

Table 2: Main features of morphological sub-zones within the weathering profile over the prophyritic biotite granite

\begin{tabular}{|c|c|c|}
\hline Sub-zone & Depth along slope $(\mathrm{m})$ & Morphological features \\
\hline IA & $0.0-0.84$ & Brownish yellow, porous, subangular blocky, sandy clay with many roots \\
\hline IB & $0.84-2.76$ & Reddish yellow, firm, subangular blocky, sandy clay with some roots \\
\hline IC & $2.76-12.96$ & $\begin{array}{l}\text { Yellowish red, stiff to very stiff, subangular blocky, clayey sand. Indistinct relict quartz veins. Indistinct } \\
\text { to distinct, relict bedrock textures }\end{array}$ \\
\hline IIA & $12.96-17.28$ & $\begin{array}{l}\text { Yellowish red, friable, gravelly silty sand with thin bands and wedges of yellowish red, stiff gravelly sandy } \\
\text { clay. Distinct relict bedrock texture and quartz veins. Indistinct relict joint planes }\end{array}$ \\
\hline IIB & $17.28-24.84$ & $\begin{array}{l}\text { Pinkish to yellowish, friable, gravelly silty sand with thin bands of yellowish red, gravelly silty sand } \\
\text { Distinct relict bedrock texture, quartz veins and joint planes. Indistinct relict fault planes. Some weathered } \\
\text { coreboulders }\end{array}$ \\
\hline IC & 24.84-33.12 & $\begin{array}{l}\text { Whitish to pinkish, friable, gravelly silty sand with distinct relict bedrock texture, quartz veins, joint and } \\
\text { fault planes. Many partly weathered and unweathered coreboulders present ( }<50 \% \text { by area) }\end{array}$ \\
\hline IID & $33.12-49.20$ & $\begin{array}{l}\text { Mainly partly weathered to unweathered, rounded coreboulders ( }>70 \% \text { area) with thin to broad bands of } \\
\text { whitish to pinkish, friable, gravelly silty sand with distinct relict bedrock texture, quartz veins, joint and } \\
\text { fault planes }\end{array}$ \\
\hline IIIA & $49.2-54.0$ & $\begin{array}{l}\text { Continuous granite bedrock outcrop with thin strips and wedges of whitish, friable, gravelly silty sand } \\
\text { along joint and fault planes }\end{array}$ \\
\hline IIIB & $>54.00$ & $\begin{array}{l}\text { Continuous granite bedrock outcrop with thin strips of whitish, friable, gravelly silty sands along joint and } \\
\text { fault planes }\end{array}$ \\
\hline
\end{tabular}

also seen within the bedrock. The grey bedrock is medium to coarse grained and usually porphyritic with large alkali feldspar phenocrysts (up to $4 \mathrm{~cm}$ in length). The essential minerals are quartz, alkali feldspar, plagioclase feldspar and biotite, whilst the accessory minerals include apatite, tourmaline and zircon. Quartz occurs as anhedral crystals, filling interstices in the groundmass and sometimes forms small phenocrysts. The alkali feldspars include microcline, orthoclase and perthites and occur both as phenocrysts and as fine to medium grained crystals in the groundmass. The alkali feldspars sometimes contain quartz, biotite and plagioclase inclusions. The plagioclase feldspars, of an albite to andesine composition, are usually found as euhedral to subhedral, fine to medium grained crystals in the groundmass and are often sericitized. The biotites occur as fine to medium grained, generally euhedral crystals and are found both as disseminated grains and as aggregates within the bedrock material. Close to the faults, hydrothermal alteration of the plagioclase feldspar and biotite grains has occurred. Modal analyses of the granitic bedrock are shown in Table 1 .

Morphological zonation of the weathering profile: Field inspection of the exposed weathering profile shows lateral and vertical variations in the degree of preservation of the minerals, textures and structures of the original granitic bedrock. Morphological criteria, including the color and texture of the weathered materials, the degree of preservation of the original bedrock textures and structures, the extent of alteration of original bedrock minerals and the percentage occurrence of litho-relicts (coreboulders), allowed differentiation of three broad Zones and several subzones within the weathering profile (Fig. 2 and Table 2). These morphological zones and sub-zones can be correlated with rock mass weathering grades as discussed in an earlier study (Raj, 1985). It is to be noted that the author prefers the morphological zonation of the weathering profile rather than the assignment of rock mass weathering grades as the morphological zonation allows recognition of relict bedrock structures; a feature of importance in discussions on the stability of slopes excavated in the earth materials of weathering profiles (Raj, 1985).

The topmost morphological Zone 1 (Grade 6) is up to $12 \mathrm{~m}$ thick and consists of completely weathered bedrock materials that indistinctly preserve the textures, but not structures, of the original bedrock. The weathered materials have resulted from the operation of both geochemical and pedochemical weathering processes and can be separated into an upper, sandy clay IA soil horizon ( $\sim .8 \mathrm{~m}$ thick), an intermediate, firm, sandy clay IB soil horizon ( $\sim 2 \mathrm{~m}$ thick) and a lower, stiff to very stiff, clayey sand, IC soil horizon (or saprolite) (up to $10 \mathrm{~m}$ thick).

The intermediate morphological Zone II (Grades 3, 4 and 5) is up to $30 \mathrm{~m}$ thick and consists of in situ moderately to highly weathered bedrock materials that indistinctly to distinctly preserve the minerals, textures and structures of the original bedrock; the degree of preservation increasing with depth. This Zone can be separated into four sub-zones; the top two sub-zones 
Am. J. Geoscience 1 (1): 12-20, 2010

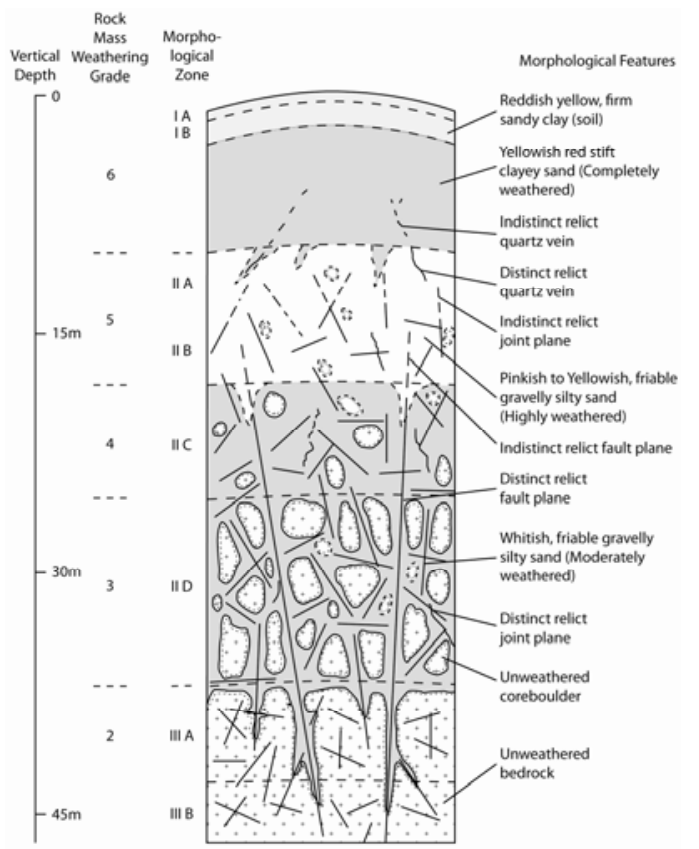

Fig. 2: Schematic sketch showing the main features of morphological zones and sub-zones within the weathering profile over the porphyritic biotite granite

IIA and IIB consisting mainly of friable, gravelly silty sands with distinct relict bedrock textures and quartz veins, but indistinct relict fracture planes. The upper IIA sub-zone is up to $6 \mathrm{~m}$ thick and devoid of coreboulders, whilst the lower IIB sub-zone is some $7 \mathrm{~m}$ thick and contains a few weathered coreboulders. In the lower sub-zones IIC and IID, unweathered coreboulders are prominent and separated by thin to broad, bands of friable, gravelly silty sands showing distinct relict bedrock textures and structures. Unweathered coreboulders form up to some $50 \%$ by area of sub-zone IIC ( $\sim 8 \mathrm{~m}$ thick), but constitute more than $70 \%$ of the lower IID sub-zone.

The bottom morphological Zone III (Grade 2) is distinct from Zone II and consists of a continuous bedrock outcrop with effects of weathering along and between, structural discontinuity planes. An upper IIIA sub-zone ( $\sim 5 \mathrm{~m}$ thick) can be distinguished where effects of weathering are seen as narrow to broad, strips and wedges of friable, gravelly silty sands with distinct relict bedrock textures and structures, whilst in the lower IIIB sub-zone, weathering effects are only marked by thin strips of friable, gravelly silty sands along discontinuity planes.

The morphological zones and sub-zones are developed approximately parallel to the overlying ground surface; being of maximum thickness below the ridge crest and thinning towards the valley sides. The continuous granitic bedrock outcrop of Zone III has required the use of explosives for its excavation, though this has not been the case for the earth materials of morphological Zones I and II, except for a few large coreboulders. Morphological Zones I and II thus represent the 'residual soil' over the bedrock according to the definition in the USBR Earth Manual (United States Bureau of Reclamation, 1974).

\section{MATERIALS AND METHODS}

In order to better describe the weathering profile, constant volume samples were collected at different depths (Fig. 3) to determine the index properties of weathered materials that can be classified as 'soil' in the engineering sense (Terzaghi and Peck, 1948). These samples were collected with brass tubes of $4 \mathrm{~cm}$ length and $7.6 \mathrm{~cm}$ internal diameter; the tubes having a constant wall thickness of $0.3 \mathrm{~cm}$ except at one end where the lower half tapered to a thickness of $0.15 \mathrm{~cm}$ to provide a cutting edge. A single brass tube was first driven into the soil by hammering gently on its top until the top was flush with the ground surface. A second brass tube, with its cutting edge facing upwards, was then placed on the top of the first tube which was then driven deeper into the soil by gently hammering on the top of the second tube; a piece of wood being placed over the second tube to minimize damage to the tube and disturbance of the sample. Both tubes were then dug out from the ground by excavating the soil surrounding and underlying the tubes. The upper tube was then gently removed to leave the lower tube with the sample which was then trimmed and sealed with rubber discs that were held in place by screwed-on metal plates. Prior to sampling, the tubes were externally greased to facilitate entry into the soil, whilst materials on the slope were excavated to a depth of some $0.5 \mathrm{~m}$ to minimize surface disturbance. Prior to sampling, the soil was also trimmed into an approximately cylindrical shape, slightly larger than the tube diameter, to reduce lateral compaction. The sealed tubes were taken to the laboratory where the samples were extracted and their bulk and dry densities as well as moisture contents determined. Specific gravity determinations of the solid mineral grains and particle size distributions of the samples, as well as the plastic and liquid limits of the fine fractions were then determined according to standard methods (American Society For Testing Materials, 1970).

Samples for determination of the soil-moisture retention curves (using the pressure plate method) were also collected in the same way as those for determination of the index properties. Samples from the sealed tubes were extracted in the laboratory and cut into 5 pieces of about similar volumes which were 


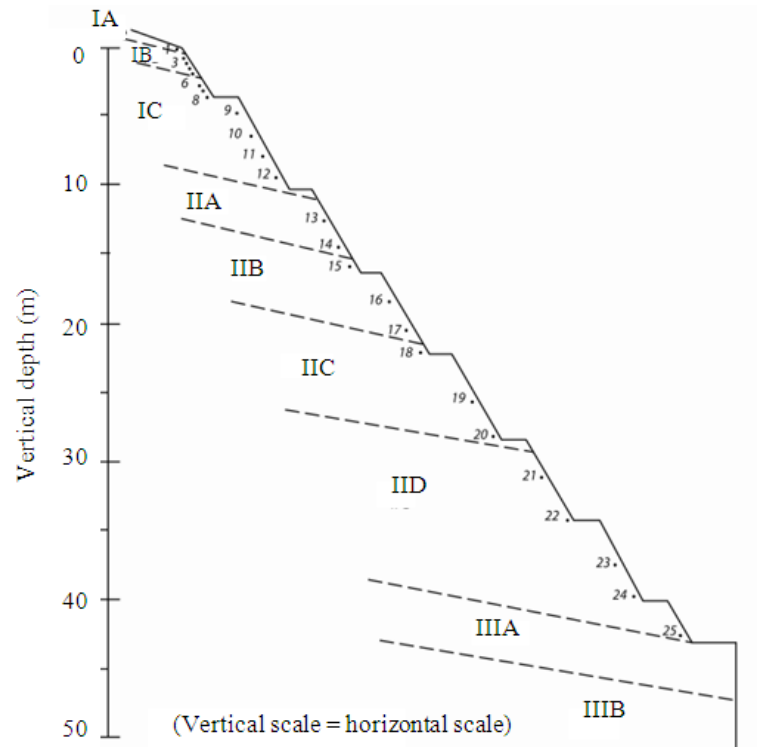

Fig. 3: Sample locations and lateral extensions of morphological zones and sub-zones within the weathering profile over the porphyirtic biotite granite

then saturated with water by placing them on a wire gauze in a tray of water; the water level just touching the base of the samples. For complete saturation, the samples were left to stand overnight. The moisture content of one of the five saturated samples was determined, whilst the remaining four saturated samples were placed on water saturated ceramic porous plates in four separate chambers. The air pressures in the pressure chambers were then adjusted to subject the samples to different pressures; the lower side of the porous plates being exposed to atmospheric pressure. The pressures were kept constant for one week until the overflow of excess water had stopped. After release of the pressures, the samples were removed and their moisture contents then determined. The pressure plate tests were carried out at the Soils Laboratory of the then University Pertanian Malaysia (now University Putra Malaysia) where such tests were being routinely conducted for agricultural soil surveys. Results of the tests were thus provided in terms of gravimetic moisture contents and $\mathrm{pF}$ suction units; the $\mathrm{pF}$ value being the 10-base logarithm of suction in centimeters of water column h, i.e., $\mathrm{pF}=\log _{10}(-\mathrm{h})$.

Soil suction or soil moisture tension, which is a negative pressure, is the most important soil moisture characteristic for a growing plant and is usually defined in units of bars (where $1 \mathrm{bar}=100 \mathrm{kPa}$ ). A saturated soil has a soil moisture tension of about 0.001 bars or less, whilst at field capacity, most soils have a soil moisture tension between 0.05 and 0.33 bars; field capacity being defined as the level of soil moisture left in the soil after drainage of gravitational water which frequently takes a few days to drain through the soil profile. The wilting point, which is defined as the soil moisture content where most plants cannot exert enough force to remove water from small pores in the soils, is at about 15 bars soil moisture tension for most agronomic crops. Water, held between field capacity and the wilting point is available for plant use, whilst capillary water held in the soil beyond the wilting point can only be removed by evaporation (Mohamed et al., 2006). In view of these relationships, results of soilwater retention curves are also often expressed in terms of 'quick' and 'slow' drainage pores as well as 'storage' pores; these values being determined from the following equations:

Quick drainage pores (\%) = Moisture content $(\mathrm{pF} 0.0)$ moisture content ( $\mathrm{pF}$ 2.0)

Slow drainage pores $(\%)=$ Moisture content $(\mathrm{pF} 2.0)$ moisture content ( $\mathrm{pF}$ 2.54) $\begin{aligned} \text { Storage pores }(\%)= & \text { Moisture content }(\mathrm{pF} \text { 2.54)- } \\ & \text { moisture content }(\mathrm{pF} 4.19)\end{aligned}$

\section{RESULTS}

Index properties of earth materials ('soil') within the weathering profile show vertical variations and demarcate more clearly the different morphological zones and sub-zones (Table 3). Specific gravity values of the solid mineral grains, however, do not show much variation, ranging from 2.59-2.63; a range that is not unexpected in view of the weathered and original, bedrock minerals present, that include kaolinite, sericite, biotite, quartz, alkali and plagioclase feldspars (Raj, 1985).

The earth materials of morphological Zone I are quite distinct from those of Zone II, being characterized by large clay and silt contents in contrast to the large sand and silt contents of Zone II. Sub-zones (horizons) IA and IB furthermore, are characterized by sandy clays of low densities (1.0-1.3 $\mathrm{g} \mathrm{cm}^{-3}$ dry density) and high porosities (>50\%), whilst 
Am. J. Geoscience 1 (1): 12-20, 2010

Table 3: Index properties of earth materials in the weathering profile over the porphyritic biotite granite

\begin{tabular}{|c|c|c|c|c|c|c|c|c|c|c|c|}
\hline $\begin{array}{l}\text { Sampling } \\
\text { point }\end{array}$ & $\begin{array}{l}\text { Morpho- } \\
\text { logical zone }\end{array}$ & SG Particles & $\begin{array}{l}\text { Bulk density } \\
\left(\mathrm{g} \mathrm{cm}^{-3}\right)\end{array}$ & $\begin{array}{l}\text { Dry density } \\
\left(\mathrm{g} \mathrm{cm}^{-3}\right)\end{array}$ & Porosity (\%) & $\begin{array}{l}\text { Plastic } \\
\text { limit }\end{array}$ & $\begin{array}{l}\text { Liquid } \\
\text { limit (\%) }\end{array}$ & $\begin{array}{l}\text { Clay } \\
(\%)\end{array}$ & $\begin{array}{l}\text { Silt } \\
(\%)\end{array}$ & $\begin{array}{l}\text { Sand } \\
(\%)\end{array}$ & $\begin{array}{l}\text { Gravel } \\
\text { (\%) }\end{array}$ \\
\hline 1 & IA & 2.59 & 1.25 & 1.00 & 61 & 35 & 73 & 52 & 6 & 42 & 0 \\
\hline 2 & IB & 2.59 & 1.49 & 1.21 & 53 & 35 & 73 & 52 & 8 & 40 & 0 \\
\hline 3 & IB & 2.59 & 1.55 & 1.23 & 52 & 36 & 74 & 44 & 17 & 39 & 0 \\
\hline 4 & IB & 2.59 & 1.57 & 1.23 & 53 & 38 & 82 & 52 & 13 & 35 & 0 \\
\hline 5 & IB & 2.59 & 1.67 & 1.35 & 48 & 37 & 82 & 48 & 14 & 37 & 1 \\
\hline 6 & IC & 2.61 & 1.89 & 1.67 & 36 & 38 & 84 & 30 & 14 & 55 & 1 \\
\hline 7 & IC & 2.63 & 1.79 & 1.55 & 41 & 37 & 85 & 30 & 17 & 44 & 9 \\
\hline 8 & IC & 2.63 & 1.88 & 1.63 & 38 & 33 & 76 & 26 & 22 & 47 & 5 \\
\hline 9 & IC & 2.63 & 1.79 & 1.61 & 39 & 35 & 69 & 23 & 22 & 48 & 7 \\
\hline 10 & IC & 2.63 & 1.87 & 1.69 & 36 & 34 & 69 & 19 & 24 & 48 & 9 \\
\hline 11 & IC & 2.62 & 1.81 & 1.63 & 38 & 34 & 67 & 13 & 27 & 45 & 15 \\
\hline 12 & IC & 2.61 & 1.90 & 1.63 & 38 & 35 & 55 & 15 & 33 & 44 & 8 \\
\hline 13 & IIA & 2.59 & 1.44 & 1.27 & 51 & 33 & 60 & 6 & 18 & 64 & 12 \\
\hline 14 & IIA & 2.60 & 1.44 & 1.29 & 51 & 40 & ind & 9 & 25 & 60 & 6 \\
\hline 15 & IIB & 2.60 & 1.56 & 1.38 & 47 & 39 & ind & 9 & 23 & 63 & 5 \\
\hline 16 & IIB & 2.60 & 1.46 & 1.29 & 50 & 41 & ind & 8 & 20 & 62 & 10 \\
\hline 17 & IIB & 2.60 & 1.40 & 1.28 & 51 & 43 & ind & 3 & 26 & 61 & 10 \\
\hline 18 & IIC & 2.53 & 1.32 & 1.15 & 55 & 40 & ind & 10 & 29 & 50 & 11 \\
\hline 19 & IIC & 2.53 & 1.30 & 1.15 & 55 & 44 & ind & 5 & 25 & 63 & 7 \\
\hline 20 & IIC & 2.59 & 1.38 & 1.28 & 50 & 42 & ind & 7 & 25 & 51 & 17 \\
\hline 21 & IID & 2.63 & 1.49 & 1.35 & 49 & 42 & ind & 6 & 25 & 66 & 3 \\
\hline 22 & IID & 2.59 & 1.51 & 1.35 & 48 & 36 & ind & 5 & 22 & 57 & 16 \\
\hline 23 & IID & 2.61 & 1.51 & 1.42 & 46 & 37 & ind & 5 & 15 & 64 & 16 \\
\hline 24 & IID & 2.59 & 1.54 & 1.44 & 45 & 37 & ind & 3 & 17 & 72 & 8 \\
\hline 25 & IID & 2.60 & 1.50 & 1.41 & 46 & 27 & ind & 6 & 12 & 79 & 3 \\
\hline
\end{tabular}

Note: SG: Specific Gravity of soil particles; ind: indeterminate with Casagrande apparatus

Table 4: Moisture contents at different suctions of earth materials from the weathering profile over the porphyritic biotite granite

\begin{tabular}{|c|c|c|c|c|c|c|}
\hline Sampling point & Morphological sub-zone & $\begin{array}{l}\mathrm{pF} \mathrm{0}(0 \mathrm{kPa}) \\
(\%)\end{array}$ & $\begin{array}{l}\mathrm{pF} 1(0.98 \mathrm{kPa}) \\
(\%)\end{array}$ & $\begin{array}{l}\mathrm{pF} 2(9.8 \mathrm{kPa}) \\
(\%)\end{array}$ & $\begin{array}{l}\mathrm{pF} 2.54(33 \mathrm{kPa}) \\
(\%)\end{array}$ & $\begin{array}{l}\mathrm{pF} 4.19(1500 \mathrm{kPa}) \\
(\%)\end{array}$ \\
\hline 8 & IC & 34.50 & 29.25 & 27.35 & 20.2 & 17.95 \\
\hline 15 & IIB & 32.00 & 28.25 & 18.3 & 15.1 & 6.35 \\
\hline 17 & IIB & 31.00 & 30.30 & 20.0 & 14.0 & 7.60 \\
\hline 22 & IID & 26.80 & 23.55 & 17.5 & 13.3 & 3.90 \\
\hline 25 & IID & 21.85 & 18.90 & 11.8 & 7.8 & 2.75 \\
\hline
\end{tabular}

sub-zone IC is characterized by clayey sands of high densities (dry density $>1.55 \mathrm{~g} \mathrm{~cm}^{-3}$ ) and low porosities (36-41\%). This difference is expected in view of the fact that the earth materials of sub-zones IA and IB represent the "solum proper" or "layer of active soil formation”, whilst sub-zone IC forms the saprolite (or parent material) for the over-lying soil horizons and has thus been influenced by processes of both geochemical and pedochemical weathering (Carrol, 1970). The high clay contents in sub-zone IC thus result from not only the alteration of bedrock minerals but also from the illuviation of clays from the over-lying soil horizons. The fine fractions of earth materials in Zone I yield plastic limits of around $37 \%$ and liquid limits between 67 and 85\%, moisture content; values that reflect the presence of kaolinite (whose presence is confirmed by X-ray diffractograms) (Raj, 1985).

The earth materials (gravelly sandy silts) of morphological Zone II also show variations in texture with depth; there being a gradual increase in clay and silt fractions up the weathering profile, but a corresponding decrease in the sand fractions. These variations in texture reflect increasing effects of geochemical weathering processes up the profile with X-ray diffractograms showing kaolinite to be the only clay mineral present in sub-zones IIA and IIB, but kaolinite and sericite to be present in sub-zones IIC and IID (Raj, 1985). The Zone II earth materials also show variable densities and porosities; dry density ranging from 1.15-1.44 $\mathrm{g} \mathrm{cm}^{-3}$ and porosity ranging from 45$51 \%$. There is, however a gradual increase in porosity and a decrease in density, up the weathering profile (thus reflecting increasing effects of weathering processes) with porosities of 45 and 51\%, as well as dry densities of 1.50 and $1.28, \mathrm{~g} \mathrm{~cm}^{-3}$, in sub-zones IID and IIA, respectively. The high silt contents in the fine fractions of the Zone II earth materials furthermore, prevent realistic determination of the Liquid Limits employing the Casagrande apparatus (American Society For Testing Materials, 1970).

Textural variations within the weathering profile are also reflected in the results of the soil-moisture 
Am. J. Geoscience 1 (1): 12-20, 2010

Table 5: Volume percentages of drainage and storage pores in earth materials from the weathering profile over the porphyritic biotite granite

\begin{tabular}{llllll}
\hline Sampling point & Morphological sub-zone & Quick drainage pores (\%) & Slow drainage pores (\%) & Total drainage pores (\%) & Storage pores (\%) \\
\hline 8 & IC & 7.15 & 7.15 & 14.30 & 2.25 \\
15 & IIB & 13.70 & 3.20 & 16.90 & 8.75 \\
17 & IIB & 11.00 & 6.00 & 17.00 & 6.00 \\
22 & IID & 9.30 & 4.20 & 13.50 & 9.40 \\
25 & IID & 10.05 & 4.00 & 14.05 & 5.05 \\
\hline
\end{tabular}

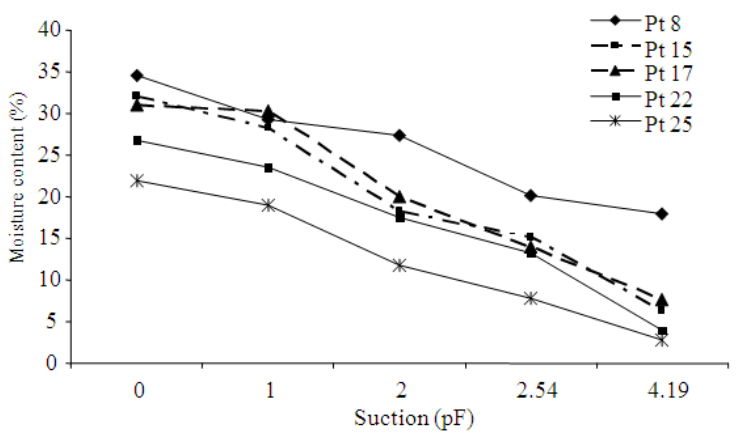

Fig. 4: Soil-moisture retention curves of earth materials in the weathering profile over the porphyritic biotite granite

retention curves (Table 4 and Fig. 4). The clayey sand from sub-zone IC shows increasing values of suction from 0-4.19 $\mathrm{pF}(0-1,500 \mathrm{kPa})$ with decreasing moisture contents from $35-18 \%$, whilst the gravelly silty sands from sub-zones IIB and IID, show similar increasing values of suction but with decreasing moisture contents from $32 \%$ to about $7 \%$ and from $25 \%$ to about $4 \%$, respectively. At the maximum suction of $\mathrm{pF} 4.19$ measured furthermore, the moisture content in the subzone IIB samples is about $7 \%$ whilst that in the subzone IID samples is about $4 \%$ and that in the sub-zone IC samples is about $18 \%$. As moisture contents lower than the value at saturation give rise to suction (or negative pore water pressures), it is expected that the earth materials of sub-zone IC will have higher shear strengths (being cohesive) in comparison with the earth materials from sub-zones IIB and IID that maybe termed 'cohesionless' soils.

Textural variations in the weathering profile also give rise to distinct differences in the volumes of 'drainage' and 'storage' pores calculated from the results of the soil-moisture retention curves (Table 5). The large drop in moisture content (about 11\%) for samples from sub-zones IIB and IID between suctions of pf 0 and $\mathrm{pF} 2$ indicates the presence of a large volume of 'quick drainage pores' in contrast to the sample from sub-zone IC which shows a smaller drop of some $7 \%$ for the same values of suction. The volume of slow drainage pores for all samples, however, appears to be about the same with somewhat similar drops in moisture content of between 5 and 7\% between suctions of $\mathrm{pF} 2$ and $\mathrm{pF}$ 2.54. The volume of storage pores is also distinctly different with the samples of sub-zones IIB and IID showing much larger values than the sample from sub-zone IC.

\section{DISCUSSION}

From the results just described, it is clear that there is a vertical variation in the earth materials present and original bedrock minerals, textures and structures preserved, at different levels within the weathering profile; the variations reflecting the increasing effects of geochemical and pedochemical weathering processes up the profile. Discussions on the index properties and soil-water retention capacities, of earth materials within the weathering profile (and residual soil) have therefore, to be carried out with reference to the locations of samples. Discussions without reference to the locations of samples in the weathering profiles and residual soils of humid tropical areas can therefore, be misleading given the considerable variation in textures and other features within them.

Results of the soil-moisture retention curves show variations with location of samples; a feature that is supported by a study involving the daily measurements of suction, moisture and temperature as well as rainfall, between 25/01/1992 and 12/05/1992 at depths of 30, 92 and $124 \mathrm{~cm}$ in morphological sub-zones IC, IIA, IIB and IIC of the weathering profile being discussed (Ali et al., 2005; Bujang et al., 2005). The study showed the value of suction to vary with depth and soil weathering grade; earth materials of sub-zone IC generally having the highest values of suction and those of sub-zone IIC having the lowest values. These differences in suction were attributed to differences in infiltration rates; subzone IC having the slowest rates and sub-zone IIC having the fastest rates (Bujang et al., 2005). The present study has shown that there are differences in the volumes of the 'quick drainage' pores present in the earth materials at different levels of the weathering profile; a feature which influences the rate of infiltration of rainwater into and rate of percolation of water through, the earth materials. In view of differences in the volumes of the 'quick drainage' pores, it is expected that the earth materials of sub-zone IC will have the lowest rates of infiltration and percolation, whilst those of sub-zones IIA and IIB will 
be of intermediate values and those of sub-zones IIC and IID have the fastest rates.

Differences in the volumes of the 'drainage' pores furthermore, can be correlated with the types of failures that have occurred at slope cuts excavated in similar weathered materials in the granitic bedrock areas of Peninsular Malaysia. A published study has noted that most of the failures occur during, or following, short periods $(<3 \mathrm{~h})$ of intense rainfall, or longer periods ( $>1$ day) with somewhat continuous rainfall; the failures often occurring when total daily rainfall exceeds $70 \mathrm{~mm}$ (Raj, 2003). Failures (earth falls and shallow slips) involving earth materials from morphological Zone I (with relatively low volumes of 'drainage' pores) have been preceded by the development of tension and desiccation, cracks that have increased their infiltration rates, whilst the failures (slumps, slump-flows and flow-slides) involving earth materials from morphological Zone II (with relatively large volumes of 'drainage' pores) have occurred without the development of desiccation cracks (Raj, 2003).

The soil-moisture retention curves finally show that the earth materials in the weathering profile experience increasing suction (or negative pore water pressures) with decreasing moisture contents (less than the value at saturation), i.e., when they desaturate (Vanapalli et al., 1996; Mohamed et al., 2006). Suction within unsaturated or partly saturated soils is an most important phenomenon that can be said to enhance the shear strength of the soils (Vanapalli et al., 1996); some authors considering suction to act as 'apparent cohesion (Lumb, 1975)'. In view of the vertical variations in the soil-moisture retention characteristics shown by this study, it is expected that there will be vertical variations in the role of suction in contributing to the shear strengths of the earth materials within the weathering profile. This feature is exemplified in the failures that have occurred at other slope cuts excavated in similar weathered materials in the granitic bedrock areas of Peninsular Malaysia (Raj, 2003). Failures involving the 'cohesive' earth materials of morphological Zone I have mostly occurred at cuts with steep overall slope angles $\left(>60^{\circ}\right)$, whereas failures involving the 'cohesionless' earth materials of morphological Zone II have occurred at cuts of moderate to steep overall slope angles $\left(>45^{\circ}\right)$ (Raj, 2003).

\section{CONCLUSION}

It is concluded that there is a vertical variation in the earth materials present, as well as original bedrock minerals, textures and structures preserved, at different levels within the weathering profile; the variations reflecting the increasing effects of geochemical and pedochemical weathering processes up the profile. The weathering profile can be differentiated into three broad morphological zones and several sub-zones that can be correlated with rock mass weathering grades. The topmost Zone I (Grade 6) is some $12 \mathrm{~m}$ thick and comprises completely weathered bedrock materials (mainly stiff, clayey sand) with indistinct relict bedrock textures. The intermediate Zone II (Grade 3-5) is about $30 \mathrm{~m}$ thick and consists of in situ, moderately to highly weathered bedrock materials (mostly friable, gravelly silty sands and coreboulders) that indistinctly to distinctly preserve the original bedrock minerals, textures and structures; the degree of preservation increasing with depth. The bottom Zone III (Grade 2) consists of continuous bedrock with effects of weathering only along and between structural discontinuity planes; the earth materials of Zones I and II thus representing the residual soil over bedrock. Constant volume samples show a general increase in porosity, silt and clay fractions up the weathering profile, but a corresponding decrease in the sand and gravel fractions with sub-zone IC having the highest density and lowest porosity.

Soil-moisture retention curves, determined with the pressure plate method, show increasing suctions from 0 - $4.19 \mathrm{pF}$ (0 to $-1,500 \mathrm{kPa}$ ) with decreasing moisture contents of $35-18 \%$ for sub-zone IC samples, $32-7 \%$ for sub-zone IIB samples and some $25-4 \%$ for sub-zone IID samples. These soil-moisture retention variations reflect textural differences and point to the inherent role of suction in the unsaturated earth materials. Differences in the volumes of calculated drainage and storage pores indicate that the earth materials of sub-zone IC will have the lowest rates of infiltration and percolation, whilst those of sub-zone IID will have the fastest rates and those from sub-zone IIB, intermediate rates.

\section{ACKNOWLEDGEMENT}

Financial support for the preparation of this research from the University of Malaya Research Grant 043/09AFR is gratefully acknowledged.

\section{REFERENCES}

Agus, S.S., E.C. Leong and H. Rahardjo, 2001. Soilwater characteristic curves of Singapore residual soils. Geotech. Geol. Eng., 19: 285-309. DOI: 10.1023/A:1013175913679

Ali, F.H.j., B.B.K. Huat and T.H. Low, 2005. Infiltration characteristics of granitic residual soil of various weathering grades. Am. J. Environ. Sci., 1: 64-68. ISSN: 1553-345X

American Society For Testing Materials, 1970. Special Procedures For Testing Soil And Rock For Engineering Purposes. Spec. Publ. 479, A.S.T.M., Philadephia, ISBN: 0-8031-0054-x, pp: 630. 
Bujang, B.K.H., F.H.j. Ali and S. Hashim, 2005. Modified shear box test apparatus for measuring shear strenth of unsaturated residual soil. Am. J. Applied Sci., 2: 1283-1289. ISSN: 1546-9239

Bujang, B.K.H., F.H.j. Ali, S. Hashim and A. Abdullah, 2005. Response of suction, moisture and temperature of unsaturated granitic residual soil to rainfall. Elect. J. Geotech. Eng., 10: 0545. ISSN: 1089-3032

Carrol, D., 1970. Rock Weathering, Plenum Press, New York, ISBN: 0306304341, pp: 203.

Lumb, P., 1975. Slope failures in Hong Kong. Q. J. Eng. Geol., 8: 31-36. $\quad$ DOI: 10.1144/GSL.QJEG.1975.008.01.02

Mohamed, T.A., F.H.j. Ali, S. Hashim and B.B.K. Huat, 2006. Relationship between shear strength and soil water characteristic curve of an unsaturated grantic residual soil. Am. J. Environ. Sci., 2: 142-145. ISSN: 1553-345X

Raj, J.K, 1985. Characterisation of the weathering profile developed over a porphyritic biotite granite bedrock in Peninsular Malaysia. Bull. Int. Assoc. Eng. Geol., 32: 121-128. DOI: 10.1007/BF02594775
Raj, J.K., 2003. Guidelines to prevention of slope failures in granitic bedrock areas of Malaysia. Bull. Geol. Soc. Malaysia, 46: 11-17. ISSN: 0126-6187

Raj, J.K., 2009. Geomorphology. In: Geology of Peninsular Malaysia, Hutchison, C.S. and D.N.K. Tan (Eds.). University Malaya and Geol. Soc. Malaysia, ISBN: 978-983-44296-6-9, pp: 5-29.

Terzaghi, K. and R.B. Peck, 1948. Soil Mechanics in Engineering Practice, 1st Edn., John Wiley and Sons Inc., pp: 566.

United States Bureau of Reclamation, 1974. Earth Manual, 2nd Edn., United States Govt. Printing Office, Washington, pp: 810.

Vanapalli, S.K., D.G. Fredlund, D.E. Pufahi and A.W. Clifton, 1996. Model for the prediction of shear strength with respect to soil suction. Can. Geotech. J., 33: 379-392. DOI: 10.1139/cgj-33-3-379

Wild, A., 1993. Soils and the Environment an Introduction, Cambridge University Press, ISBN: 0-521-43280-4, pp: 287. 